\title{
EL ELEMENTO CÓMICO EN LA COMEDIA DE SANTOS (I) NOTAS SOBRE CAPRICHO, UN GRACIOSO CATECÚMENO EN EL JOSÉ DE LAS MUJERES
}

\author{
Javier Rubiera \\ Département de Littératures et de Langues Modernes \\ Université de Montréal \\ C.P. 6128 Succ. Centre Ville \\ Montreal H3C 3J7. Canada \\ javier.rubiera@umontreal.ca
}

Mis pulmones y mi corazón funcionaban o los obligaban a funcionar normalmente; lo mismo ocurría con mis intestinos, esos bufones entre los actores de nuestros autos sacramentales íntimos ${ }^{1}$.

Un gran poema dramático se parece a un organismo de primer orden, con su estructura esquelética, su anatomía de personajes y de acciones, y su sistema nervioso de ideas, alusiones, símbolos e imágenes ${ }^{2}$.

[Anuario calderoniano (ISSN: 1888-8046), 3, 2010, pp. 307-320]

$\mathrm{Si}$, por un lado, parece bien repertoriado el conjunto de técnicas y de recursos del personaje del gracioso en la Comedia, no parece que

${ }^{1}$ Vadim en Nabokov, 2001, p. 285.

2 B. Wardropper en Calderón de la Barca, El mágico prodigioso, 1996, p. 23. 
haya unanimidad crítica en torno a las funciones y al valor último de esta figura clave para el entendimiento del teatro clásico español, como no la hay sobre un tema general que enmarca a este del donaire: la función de la comicidad en la comedia. No puede haber unanimidad, porque entre 1580 y 1680 esa comedia se concretiza o manifiesta en diversos subgéneros (pastoril, palatino, urbano, devoto...), de la mano de diferentes poetas que le imponen su marca propia, en distintos espacios para la representación ante públicos también diferentes. Ante este fenómeno huidizo y cambiante, reacio a fijarse en categorías y en conceptos inalterables, ¿cómo no sospechar, además, que lo cómico, en sus variadas formas, pueda funcionar de diferente modo, por ejemplo, en un drama mitológico para palacio, que en una comedia de capa y espada para el corral o que en una comedia de santos representada en el día de Corpus en el tablado de una villa? Con este panorama a la vista, lo más sensato metodológicamente es proceder a acotar parcelas manejables que puedan ser descritas y analizadas adecuada y coherentemente, tal como dentro de la práctica escénica áurea suele hacerse, para empezar, al distinguir comedias, autos y la variada tipología de teatro breve, para los que no se pueden dar explicaciones únicas. Por eso, junto a estudios como «Funciones de la figura del donaire en el teatro de Lope», «Los recursos cómicos de Calderón», o «El gracioso en Calderón: disparate e ingenio», se encuentran otros más concretos, en grado descendente, como «El bufón en la tragedia calderoniana», «De Galindo a Coquín» o «El médico de su honra: perfil y función de Coquín», títulos todos ellos bien significativos del alcance de cada investigación.

Hay momentos para las generalizaciones y para las simplificaciones, en libros de carácter histórico que traten de ofrecer visiones de conjunto, que observen en la complejidad de los fenómenos lo que es constante o común. Pero junto a este esfuerzo generalizador es imprescindible descender de nuevo a la casuística, detenerse en los detalles y reconocer el valor de la diferencia, que a veces queda anulada por el tópico. Puede ser que después de realizar estos ensayos particulares haya que corregir la generalización. Esta dialéctica que va, repetidamente y sin descanso, de los casos a la categoría y de la categoría a los casos me parece imprescindible para el avance en nuestra disciplina. 
No todos los graciosos son iguales, a pesar de que se puedan reconocer unos procedimientos comunes, muchas veces repetidos, en el modo de producirse la comicidad. Sí hay un aire familiar que une a los graciosos, calderonianos o no, miembros todos de la «cofradía del contento». Sí hay una base común que hace que ese tipo de papeles lo identifiquemos con un solo nombre, la figura del donaire, y que apunta a un tipo de actor que se especializaría en su representación. Es evidente, entonces, que hay toda una serie de rasgos comunes propios de un "tipo", pero igualmente una serie de diferencias particulares en la construcción del gracioso de cada comedia y a partir de estudios individuales se trataría de ir viendo si es posible dentro de la comunidad de rasgos que comparte todo gracioso, hablar de una peculiaridad en el gracioso de Lope, de Tirso, de Calderón, de Moreto o de Rojas, por ejemplo. Falta mucho trabajo en este sentido, no sólo por el número de las comedias a analizar, sino porque, además, los métodos de los investigadores son a veces muy diferentes, por lo que no es posible comparar sin más las conclusiones de los estudios particulares.

Que la cuestión está lejos de resolverse, puede apreciarse en relación con la caracterización y las funciones del gracioso en la tragedia calderoniana, que en los últimos treinta años ha sido objeto de especial atención, con varios estudios concretos sobre este personaje en El pintor de su deshonra, en El médico de su honra, en La vida es sueño, en El mayor monstruo del mundo o en La hija del aire, por ejemplo. Recientemente, Ignacio Arellano ha dado una vuelta de tuerca al oponerse a la visión más generalizada, visión que insistía principalmente en la risa subversiva ${ }^{3}$ que aportaría el gracioso en el contexto trágico de la comedia:

A mi juicio la importancia de estos bufones no radica en su vertiente ideológica, sino en su anulación cómica. Están ahí para demostrar la fuerza de la tragedia que los contamina sin remedio. Una atmósfera de melancolía lo impregna todo y a todos. [...] sin abandonar las yuxtaposi-

${ }^{3}$ Me refiero aquí a los términos que Robert Jammes (1980, pp. 9-11) empleó en una famosa ponencia en el Coloquio Risa y sociedad en el teatro español del Siglo de Oro, al distinguir una risa subversiva ("la risa es, por esencia, un acto subversivo. La burla es rebelión contra el orden») de una risa conformista, "una risa recuperada por las clases dominantes y de carácter conservador». 
ciones de comicidad convencional obedientes a las expectativas del público, explora otros modos de inserción del gracioso en un juego admirable en el que la presencia extravagante e impertinente de los agentes cómicos, y el vaciamiento de su función, llega a convertirlos paradójicamente en agentes trágicos, invirtiendo su papel para expresar el cierre absoluto de unas tramas sin apertura posible a la liberación cómica ${ }^{4}$.

Por mi parte hace unos años dediqué un estudio detenido a Chato, el gracioso de La hija del aire, en el que observaba una polivalencia sobresaliente que le llevaba a cumplir funciones dramáticas muy variadas, más allá de su agencia cómica y de su intervención burlesca en momentos de alta intensidad patética. Mi atención no se fijaba tanto en discernir la relación de la esfera de lo cómico en el universo trágico o en discutir sobre la naturaleza de «lo tragicómico», a la que ha vuelto Arellano recientemente, como en subrayar su rendimiento en la economía de la comedia, su polivalencia funcional, dando razón de por qué y para qué está ahí este personaje en el artificio teatral. El hecho de que se trate de una comedia en dos partes, permitió seguir de cerca al villano Chato durante su largo viaje dramático en compañía de Semíramis, aunque se trata de un viaje anormal por la extensión inusual que permite a Calderón desarrollar más largamente su carácter y sus intervenciones. En esta ocasión trataré de aplicar los mismos principios metodológicos de aquel estudio a una pieza calderoniana perteneciente esta vez al género hagiográfico, El José de las mujeres, centrándome en la figura de Capricho con el fin de apreciar cómo Calderón utiliza en la baraja del reparto de la comedia esa valiosa carta del gracioso, un comodín que suele dar mucho juego también en el contexto festivo de la representación de carácter religioso. Sin tratar de ser un trabajo comparativo, se tendrán en cuenta como orientación los resultados del estudio sobre la tragedia de La hija del aire y se harán referencias significativas a El mágico prodigioso y a Los dos amantes del cielo, las otras dos comedias devotas más próximas genéricamente a El José, por ser dramas en los que se relata sobre escena el proceso de la conversión de un pagano al cristianismo, con su martirio consecuente y su santificación.

${ }^{4}$ Arellano, 1999, pp. 52-53. 


\section{Algunas Cuestiones metodológicas}

La introducción del donaire en el drama serio, e incluso trágico, se reconoce como una de las señas de identidad del arte nuevo codificado por Lope de Vega, aunque en su famoso discurso ante la Academia de Madrid no lo acabara de precisar. Ante todo esta figura provocaba risa y aligeraba la gravedad de una representación que siempre debía mantener su carácter festivo, pero el dramaturgo sabía bien que el rendimiento del donaire sobrepasaba esta función lúdica, convirtiéndose en una pieza clave de la construcción dramatúrgica ${ }^{5}$. El comediógrafo compone su obra como un "poema dramático representable», es decir, teniendo en cuenta que es un poema, que es un drama y que será un espectáculo, y en vista de la representación que se dará, y no únicamente de las necesidades internas de la acción dramática, incluye un papel que desempeña uno de los actores más importantes de la compañía. Ya en época de Lope se recordó esa asociación del personaje a la malilla ${ }^{6}$, que a mí me parece tan sugerente, al verlo como un comodín o joker que puede utilizarse en cantidad de situaciones diferentes y que se mueve con gran libertad escénica, tanto fisica como verbal. En cada pieza el poeta le dota de un carácter y le confiere unas funciones que lo van construyendo como personaje diferenciado dentro de la misma familia de graciosos. En aquellos dramas de carácter serio - tragedias y comedias devotas, por ejemploes esta figura la responsable de concentrar las intervenciones cómicas, a diferencia de otro tipo de comedias en las que la comicidad está dispersa y se reparte en diversos agentes. Pero pueden ser muchas más las responsabilidades del gracioso. Su polivalencia, a la que me refería más arriba, se manifiesta en el hecho de que a su valor sintáctico, re-

${ }^{5}$ Retomo en este párrafo el enfoque metodológico que presentaba al comienzo de «Función cómica y funciones dramáticas del gracioso en La hija del aire» (Rubiera, 2005, pp. 226-227).

${ }^{6}$ Lázaro Carreter (1987, p. 46) lo había señalado en su artículo sobre el gracioso: «El Tristán de La francesilla declara ser "malilla / en todas las ocasiones". En El castigo sin venganza, es el criado quien llama a Lucrecia también "malilla". Ambos son, en efecto, malillas, esto es, naipes que se usan a voluntad por el que juega». Lázaro Carreter recordaba que en el Diccionario de Autoridades se aportaba un texto del Guzmán de Alfarache para asegurar la acepción: "Figúraseme ahora que debía de ser entonces como la malilla en el juego de los naipes, que cada uno la usa cómo y cuándo quiere». 
forzando las relaciones entre los diferentes personajes o sirviendo de enlace entre accciones distantes, se le añade un valor pragmático muy claro, al articular irónicamente la relación del dramaturgo y de su poema con el público, señalando con sus comentarios la naturaleza lúdica del artificio teatral. Sin embargo, al ver el elemento cómico como algo incongruente con la gravedad del tema o al interpretarlo como superfluo o impertinente, la lectura moderna minusvalora en ocasiones la relevancia de la comicidad y de su agente principal. Su presencia, no obstante, parece necesaria para dar cuenta de la compleja visión del mundo del dramaturgo barroco, que no la utiliza únicamente como adorno divertido en la representación o por seguir ciegamente las convenciones de cierta escritura poética o para satisfacer las demandas de un poderoso público habituado a ella. Además, aquella precisión de mecanismo de relojería tantas veces alabada en Calderón no se lograría del mismo modo si esta graciosa pieza no funcionara bien lubricada y ajustada en el engranaje escénico. Si en principio puede reconocerse con A. A. Parker «el hecho de que la primera tarea de un crítico literario es comprender un texto desde la perspectiva de la idea de la época que lo produjo» ${ }^{7}$, es imprescindible valorar adecuadamente el carácter y las funciones del gracioso para aprehender también en todo su valor los dramas serios — tragedias y comedias religiosas- del siglo XVII.

Una de las ideas motoras en mi acercamiento al estudio del personaje del gracioso es reconocer que cuando Calderón escribe sus comedias ya existe tras él una larga tradición, que ha ido transformándose sobre todo desde finales del XVI, por la que cuenta con una serie de fórmulas, de procedimientos o de recursos cómicos, tanto físicos como verbales que son manejados con maestría por un tipo de actor que se ha especializado en determinados papeles. Se trata de chistes, juegos de palabras, cuentecillos folklóricos, bofetadas, saltos, disfraces, alusiones infalibles a médicos, esposas y sastres ... de efecto bien probado en el público de cientos de comedias, pero también de entre-

7 Corrijo aquí un error deslizado en mi artículo sobre Chato (Rubiera, 2005, p. 227), en el que adjudicaba yo estas palabras a I. Arellano (1999, p. 336), quien realmente remataba su libro sobre la convención y recepción con una cita de Parker con la que decía coincidir plenamente. 
meses y de autos ${ }^{8}$. A ese repertorio tradicional se añaden lances originales y juegos de ingenio creados para la nueva ocasión, en relación más concreta con la acción y con los otros personajes de cada comedia particular. El dramaturgo dispone esas intervenciones casi siempre a lo largo de las tres jornadas y entrega en su poema dramático unos cientos de versos, en el mejor de los casos, con pocas indicaciones escénicas directas o acotaciones, para que un actor, que conoce bien este tipo de papeles, construya su personaje sobre el tablado' 9 . A partir de esos versos, según su propia habilidad histriónica y siguiendo las convenciones que comparte con su público, realiza su actuación. A veces lo que le entrega el poeta es insuficiente para crear un personaje y todo se queda en una sucesión mejor o peor engarzada de chistes, bromas o burlas dispersas. ¿Qué podría hacer un gracioso con el puñado de versos y de situaciones que tiene Brito en El príncipe constante? Otras veces se aprecia que el poeta ha cuidado más al personaje cómico: le da una buena extensión de versos — digamos unos cuatrocientos-, mantiene su presencia con continuidad y con cierta lógica, concentra sus intervenciones jocosas en torno a un tema o guiño que se repite y que le da motivo al actor para su trabajo de caracterización. En esos casos, como Escarpín en Los dos amantes del cielo o Capricho en El José de las mujeres, el actor se encuentra con un auténtico "caramelo", de éxito asegurado a poco que se emplee bien en su arte.

Si, para empezar, nos fijamos en las tres comedias hagiográficas de Calderón, observaremos una primera diferencia simplemente al notar que en El mágico prodigioso la comicidad se despliega en varios agentes - Clarín, Moscón y Livia - que, entre otros chistes y pasos cómicos, llevan a cabo una acción paralela de tipo paródico respecto a

${ }^{8}$ Por ejemplo, Arellano en 1986, recogiendo una observación de Profeti en el Coloquio de Toulouse de 1980 antes referido, clasifica el repertorio de estos recursos de «la comicidad escénica en Calderón» en once apartados bien indicativos: elementos paralingüísticos, gesto, prosémica, espacio escénico y escenografía, vestuario, maquillaje y peinado, figuras ridículas, objetos accesorios, música y canciones, iluminación, ruptura humorística de la ilusión escénica. Este importante artículo apareció primeramente en el número 88 de Bulletin Hispanique y se recogió años más tarde en Convención y recepción (1999, pp. 264-314).

${ }^{9}$ Coincido aquí con algunos de los planteamientos de Ruano de la Haza (2005) al caracterizar la figura del donaire en La villana de Getafe. 
la de otros personajes serios. En El José de las mujeres y en Los dos amantes del cielo, sin embargo, se concentra la comicidad prácticamente en un solo personaje de gracioso. Por otra parte, Calderón propone una caracterización bien diferente para Capricho y para Escarpín: este se construye principalmente en torno al hecho de que es un cuentista consumado y, así, sus réplicas están trufadas de cuentecillos probablemente de origen folklórico. Hasta ocho llega a contar. Aparte de este rasgo caracterizador, base para que el actor estructure su actuación, Calderón le proporciona una escena de lucimiento en la parte final, cuando un león le ataca y trata de comerlo, dando lugar a una farsa burlesca que arrancaría las carcajadas del público. Chato, sin embargo, no utiliza ninguna facecia o apólogo entre sus recursos cómicos y destaca sobre todo por su comicidad lingüística, en la que sobresale especialmente el uso de los esdrújulos, como ese "catecúmeno», repetido hasta doce veces, que aparece en el título del presente trabajo como su marca de identificación. A esta significativa repetición seguramente se agarraría el actor que lo representase para armar o construir su caracterización del personaje con una exagerada e histriónica pronunciación.

A continuación realizaré un análisis minucioso del carácter y de las funciones del gracioso Capricho, análisis que se completará en un segundo artículo complementario. Por motivos de falta de espacio, me limitaré aquí a desarrollar dos puntos: dar cuenta de la presencia del gracioso en la acción de El José de las mujeres y examinar el volumen textual que ocupa (número de intervenciones verbales y disposición en las tres jornadas), observando de qué modo contribuye a establecer el peculiar ritmo cómico-serio de la pieza dramática. Para otra ocasión dejaremos el análisis del rendimiento de su nombre parlante; su papel como enlace entre personajes, acciones y espacios; los numerosos juegos verbales; el juego escénico; el uso irónico de los anacronismos; los comentarios metaficcionales y la mediación con el público; la relación con la locura y, por último, la comicidad en el contexto religioso de la fiesta teatral.

La presencia de Capricho en la acción de EL José de LAS MUJeRES

Capricho es un criado en casa del gobernador de Alejandría, gran perseguidor de los cristianos. La hija del gobernador, Eugenia, de rara 
inteligencia y que ocupa la cátedra de filosofia, lee en uno de los libros que por orden de su padre se ha incautado a los cristianos un párrafo de una epístola de San Pablo que la deja inquieta y pensativa en su estudio. Se le aparecen entonces un demonio y Eleno, viejo venerable carmelita descalzo, que intentarán convencerla, cada uno a su modo, sobre quién es el verdadero Dios. Alterada por la presencia de estas dos visiones, Eugenia derriba el bufete, gritando al tratar de evitar que desaparezcan. Todos en casa del gobernador, incluidos su padre y su hermano, comienzan a tomarla por loca, pensando que tanto estudio le altera el juicio, sobre todo cuando Eugenia les dice que los dioses comunican con ella. Mientras tanto comienza a desarrollarse un segundo enredo, en el que Cesarino, hijo del emperador, y Aurelio compiten por el amor de Eugenia. Al final del primer acto, en una escena nocturna en casa de Eugenia, Cesarino mata a Aurelio. Huye Cesarino, Eugenia se desmaya y aparece en los aires el demonio, que anuncia que va a tratar de impedir los avances de Eugenia en el conocimeinto de Dios, por lo que planea poseer el cadáver de Aurelio. Eso es lo que ocurre ante los ojos mismos del espectador ${ }^{10}$. Cuando en casa del gobernador entran todos a ver qué pasa en el cuarto de Eugenia, ésta vuelve en sí y cuenta que Cesarino ha matado a Aurelio, pero en seguida entra Aurelio (en realidad el cuerpo de Aurelio animado por el espíritu demoniaco) y desmiente con su presencia las palabras de Eugenia. Entra también Cesarino que, confuso ante un Aurelio indemne, también niega haber estado antes en los aposentos de Eugenia. Al gobernador y a los demás no les quedará duda entonces del desequilibrio mental de la joven Eugenia, a quien veremos en la segunda jornada disfrazada de hombre, buscando por los montes de la Tebaida a la comunidad cristiana de los eliotas, de los que se pensaba en el siglo XVII que eran el antecedente de los carmelitas. A partir de este punto comienzan en la comedia los enredos del Demonio (en o desde el cuerpo de Aurelio) para obstaculizar el progreso de Eugenia hacia Dios. Entre estos enredos destaca el que da nombre a la pieza, en recuerdo de un episodio bíblico: Eugenia es

${ }^{10} \mathrm{He}$ dedicado dos estudios a aclarar problemas ecdóticos y escenográficos en torno a la posesión del cadáver de Aurelio, que supone además un episodio interesantísimo de las relaciones entre censura teatral e Inquisición (Rubiera, 2006 y 2010, en prensa). 
apresada y entregada como esclavo - pues va vestida de hombre- a Melancia en quien se despiertan deseos eróticos por el esclavillo, quien al rechazarla provoca que Melancia, desairada, trate de acusarlo por haber tratado de violarla. Sin embargo, como es lógico suponer en una comedia de este género, las artimañas del demonio sólo servirán para acrecentar en Eugenia la humildad y su fe cristiana, hasta ser ejecutada por ello, muriendo entonces como una mártir. La pieza termina con dos escenas sucesivas en contraste: el demonio abandona sobre el tablado el cadáver de Aurelio, ante la sorpresa de Capricho y de Cesarino, y mientras suena la música, «descúbrese en un trono de nubes Eugenia con ángeles y va subiendo arriba», es decir, la escena de triunfo o apoteosis de la que se convertirá en Santa Eugenia.

El juego aparatoso de la tramoya, con sus vuelos y caídas violentas, es bien representativo de la estructura de oposición de fuerzas del bien y del mal en las que Eugenia se encuentra inmersa, con un Eleno que trata de protegerla de la amenaza demoniaca. En este contexto de tensión entre las fuerzas divinas y las infernales, el único que parece tener los pies en la tierra es el criado Capricho, que sirve de mediador con el público dentro del ambiente festivo de la representación religiosa. Sin ser criado de Eugenia, acompaña a la protagonista desde el palacio de su amo, el gobernador Filipo, en Alejandría hasta los montes de la Tebaida y de allí a casa de Melancia. Podría decirse que en todos los momentos clave del drama el poeta asegura que esté presente el donaire y que intervenga: cuando Aurelio irrumpe en la Tebaida para capturar a los eremitas, el gracioso está allí haciendo sus chistes como Fray padre Capricho y le conduce hasta Eugenia y Eleno, escondidos en una cueva; cuando Melancia trata de seducir al esclavillo, allí está Capricho con su inoportuno estornudo y con sus chistes; cuando Melancia acusa públicamente al esclavo-Eugenia, se introduce chiste de Capricho; cuando el demonio abandona el cuerpo de Aurelio, dejándo su cadáver en escena y espantando a Cesarino, nuevo chiste de Capricho. Por último, su presencia se mantiene hasta el final, hasta la escena de glorificación de Eugenia, rematando la comedia con los cuatro últimos versos tradicionales de despedida. 
NúMERO DE INTERVENCIONES DE CAPRICHO Y SU DISPOSICIÓN

El recuento del número de versos que dice Capricho, o en los que interviene compartiéndolos con otros personajes, es bien elocuente. La cifra total es elevada, si contamos con que el protagonismo evidente de la historia dramática pertenece a Eugenia y al Demonio: 416 versos de una comedia de 2720 . El reparto por jornadas, asegurándose el dramaturgo de su presencia significativa a lo largo de los tres actos, es la siguiente: 159 versos en la primera, 178 en la segunda y 79 en la tercera. Se trata, entonces, de un número amplio de intervenciones con una buena distribución a lo largo de la comedia, manteniéndose su aparición con constancia, aunque en la última jornada se reduzca la extensión de sus parlamentos, casi siempre chistes breves y agudos. Ejemplo concentradísimo de esta comicidad lograda con recursos mínimos sería las cinco risotadas seguidas que arrancaría al ser descubierto por Melancia, primero con un estornudo desde su escondite, luego con un chiste anacrónico y después con tres réplicas de una sola palabra (vv. 2144-2148). Cinco versos, cinco risas:

CAPRICHO

MeLANCiA

CAPRICHO

MeLANCiA

CAPRICHO

MeLANCia

CAPRICHO
Estornuda. ¡Maldito sea el tabaco y quien lo toma!

¡Cielos!, ¿qué es esto?

Capricho.

¿Qué haces aquí?

Estornudar.

¿Cómo estás aquí?

Escondido.

Creo que este es buen ejemplo — extremo, eso sí- de que no hay que fiarse únicamente de los análisis cuantitativos, pues con una gran economía de medios y con poca presencia textual (sólo un verso completo y cuatro compartidos) se logra una gran intensidad cómica, que por el efecto que produce sobre el espectador puede ser mucho más importante que una larga tirada de versos sin una real repercusión sobre el ánimo del receptor. Capricho no sólo tiene un volumen de enunciación proporcionalmente considerable sino que en muchas ocasiones es de una eficacia extraordinaria. Además en casos como los de 
esta comedia hay que subrayar que la risa no es un elemento "pegado» extrañamente y que no conduce a una comicidad dispersa que solamente se concentre en determinados momentos de la obra, en episodios aislados sin mucha relación con la fábula principal y que se pudieran extraer sin riesgo, como si de un paso o entremés intercalado se trataran. La aparición de Capricho en escena se mantiene a lo largo de la pieza y su comicidad es utilizada por el dramaturgo con regularidad, a ciertos intervalos no calculables según una regla matemática, pero sí con una repetición sostenida que le confiere un peculiar ritmo dramático en el que se entreveran con continuidad las situaciones serias de la historia de Eugenia con las cómicas de Capricho. El organismo de la comedia parece respirar según este ritmo y las metáforas de la relajación o del alivio cómicos no hacen otra cosa que jugar con esta analogía tan significativa.

\section{CONCLUSIONES PROVISIONALES}

Como resultado del análisis del carácter y de las funciones de Capricho, que completaremos en un proximo artículo, se podrían avanzar ya los siguientes puntos:

1. Que el gracioso es imprescindible dentro de la economía de la obra, como elemento de conexión entre acciones, entre espacios y entre unos personajes y otros, sobre todo entre los dos protagonistas, Eugenia y el Demonio / Aurelio;

2. Que las intervenciones cómicas distribuidas con medida y cálculo por el poeta a lo largo de las tres jornadas conceden un ritmo especial y refuerzan la estructura de la pieza, pensada para ser representada en un contexto festivo religioso, en el que a la muerte de la protagonista sigue su celebración apoteósica;

3. Que, en definitiva, Capricho contribuye a la perfección del organismo o del mecanismo de la comedia. El artificio se hace más complejo al mostrarse la sombra de la realidad escénica, añadiéndose un elemento reflexivo e inteligente a través de los comentarios en clave de humor, por parte precisamente de aquel que hace de tonto. La intervención de Capricho proporciona una dimensión añadida que da relieve a la imagen del relato plano de la peripecia de Eugenia, corazón de un drama que necesita de otros órganos menos nobles para el funcionamiento del cuerpo cómico. 


\section{Bibliografía}

Aparicio Maydeu, J., Calderón y la máquina barroca. Escenografía, religión y cultura en "El José de las mujeres», Amsterdam / Atlanta, Rodopi, 1999.

Arellano, I., Convención y recepción. Estudios sobre el teatro del Siglo de Oro, Madrid, Gredos, 1999.

- El escenario cósmico, Madrid / Frankfurt, Iberoamericana / Vervuert, 2006.

Calderón de la Barca, P., Los dos amantes del cielo, Obras completas. Tomo I. Dramas, ed. L. Astrana Marín, Madrid, Aguilar, 1951, pp. 1145-1179.

- La hija del aire, ed. F. Ruiz Ramón, Madrid, Cátedra, 1987.

- El mágico prodigioso, ed. B. W. Wardropper, Madrid, Cátedra, 1996.

— «El José de las mujeres», en J. Aparicio Maydeu, Calderón y la máquina barroca. Escenografía, religión y cultura en "El José de las mujeres», Amsterdam / Atlanta, Rodopi, 1999, pp. 15-270.

García Gómez, Á. M., "El médico de su honra. Perfil y función de Coquín», en Calderón. Actas del Congreso Internacional sobre Calderón y el teatro espanol del Siglo de Oro, ed. L. García Lorenzo, Madrid, CSIC, 1983, vol. II, pp. 1025-1037.

García Ruiz, V., «Elementos cómicos en los autos de Calderón: función y sentido», Criticón, 60, 1994, pp. 129-142.

Güntert, G., «El gracioso en Calderón: disparate e ingenio», Cuadernos Hispanoamericanos, 324, 1977, pp. 440-451.

Jammes, R., "La risa y su función social en el Siglo de Oro», en Risa y sociedad en el teatro español del Siglo de Oro, 1980, Paris, CNRS, 1980, pp. 311.

Lázaro Carreter, F., «Funciones de la figura del donaire en el teatro de Lope», en "El castigo sin venganza» y el teatro de Lope de Vega, ed. R. Doménech, Madrid, Cátedra, 1987, pp. 33-48.

Mason, T. R., «Los recursos cómicos de Calderón», en Hacia Calderón, III, Coloquio Anglogermano, Berlin / New York, W. de Gruyter, 1976, pp. 99109.

Menéndez Pelayo, M., "Calderón y su teatro", Estudios y discursos de crítica histórica y literaria, III, Teatro. Lope, Tirso, Calderón, ed. E. Sánchez Reyes, Santander, Aldus, 1941, pp. 85-303.

Nabokov, V, ¡Mira los arlequines!, ed. J. Aparicio Maydeu, Madrid, Cátedra, 2001.

Profeti, M. G., "Código ideológico-social, medios y modos de la risa en la comedia del siglo XVII", en Risa y sociedad en el teatro español del Siglo de Oro, Paris, CNRS, 1980, pp. 13-23.

Ruano de la Haza, J. M., «Un gracioso en busca de un actor: La villana de Getafe, de Lope de Vega», en La construcción de un personaje: el gracioso, ed. L. García Lorenzo, Madrid, Fundamentos / RESAD, 2005, pp. 111-122. 
Rubiera Fernández, J. «Función cómica y funciones dramáticas del gracioso en La hija del aire», en La construcción de un personaje: el gracioso, ed. L. García Lorenzo, Madrid, Fundamentos / RESAD, 2005, pp. 225-249.

- «Un demonio de ida y vuelta. Sobre la edición de las acotaciones en El José de las mujeres calderoniano", en Edad de Oro Cantabrigense. Actas del VII Congreso de la Asociación Internacional del Siglo de Oro, ed. A. Close, Madrid, AISO, 2006, pp. 545-551.

- «Teología contra dramática. A vueltas con el demonio y la censura en El José de las mujeres calderoniano», en Actas del VIII Congreso de la Asociación Internacional del Siglo de Oro, ed. A. Azaustre y S. Fernández Mosquera, 2010, en prensa.

Ruiz Ramón, F., «El bufón en la tragedia calderoniana», en Hacia Calderón. Séptimo Coloquio Anglogermano. Cambridge 1984, ed. H. Flasche, Wiesbaden, F. Steiner, 1985, pp. 102-109.

Vitse, M., «De Galindo a Coquín», en Calderón. Actas del Congreso Internacional sobre Calderón y el teatro español del Siglo de Oro, ed. L. García Lorenzo, Madrid, CSIC, 1983, vol. II, pp. 1065-1073.

WARDropper, B. W., «Las comedias religiosas de Calderón», en Estudios sobre Calderón, ed. J. Aparicio Maydeu, Madrid, Istmo, 2000, vol. II, pp. 725743. 